\title{
Night and Day Growth Hormone Levels During Treatment with Corticosteroids and Corticotrophin
}

\author{
S. N. PANTELAKIS, C. A. SINANIOTIS, S. SBIRAKIS, D. IKKOS, and S. A. DOXIADIS \\ From the Queen Anna-Maria Institute of Child Health; the Paediatric Unit, 'Aghia Sophia' Children's Hospital; and \\ the Department of Endocrinology, Evangelismos Hospital, Athens, Greece
}

\begin{abstract}
Pantelakis, S. N., Sinaniotis, C. A., Sbirakis, S., Ikkos, D., and Doxiadis, S. A. (1972). Archives of Disease in Childhood, 47, 605. Night and day growth hormone levels during treatment with corticosteroids and corticotrophin. Night and day rhythms of HGH secretion were measured in 5 children before any treatment, 10 days after prednisone administration, and 3 days after ACTH treatment.

Corticosteroids and corticotrophin were found to have a pronounced effect on the spontaneous level of $\mathrm{HGH}$ with the almost complete disappearance of the normally observed peaks during the 24 hours in the pretreatment study.

It is postulated that this disappearance of the spontaneous peaks might explain in part the growth retardation noticed in children on long-term treatment with corticosteroids or corticotrophin.
\end{abstract}

It is well known that in children long-term corticosteroid therapy results in growth retardation (Blodgett et al., 1956; Van Metre and Pinkerton, 1959; Falliers et al., 1963), and this has also been reported for corticotrophin (ACTH), though it is not generally accepted (Friedman and Strang, 1966; Norman and Sanders, 1969). The mechanism of this effect remains still a controversial subject. The decreased growth hormone (HGH) secretion after insulin-induced hypoglycaemia reported in patients on long-term therapy with corticosteroids (Frantz and Rabkin, 1964; Hartog, Gaafar, and Fraser, 1964) or ACTH (Daly and Glass, 1971) has not been confirmed by others (Root et al., 1967; Morris, Jorgensen, and Jenkins, 1968; Friedman and Stimmler, 1966).

Recent studies have shown that $\mathrm{HGH}$ fluctuates during the 24 hours, with the occurrence of certain peaks, and it has been suggested that the regulatory effect of $\mathrm{HGH}$ on growth might be mediated through these peaks (Hunter and Rigal, 1966; Honda et al., 1969; Parker et al., 1969).

It was therefore thought that a study of the night and day HGH rhythm in children during treatment with prednisone and ACTH might help to elucidate whether corticosteroids and ACTH have any affect on HGH levels, and could therefore affect the rate of growth through this mechanism.

Received 29 November 1971.

\section{Material and Methods}

Five children, 3 boys and 2 girls, aged 8 to 13 years were studied. They were all admitted to hospital because of rheumatic fever with cardiac involvement, and treatment with corticosteroids was thought to be necessary. All 5 children were normal for height and weight, in good general condition, and afebrile the day of the test. In each of them a night and day rhythm of HGH was evaluated before corticosteroid therapy: on the 10th day of daily administration of prednisone at a dose of $2 \mathrm{mg} / \mathrm{kg}$, and on the $3 \mathrm{rd}$ day of treatment with an ACTH depot preparation (Cortrophin-Z, Organon) 20 units i.m. 12-hourly. Prednisone was discontinued the day before ACTH administration was started. The time of drug administration was prednisone 6 a.m., 12 noon, 6 p.m., and 12 midnight, and ACTH 8 a.m. and 8 p.m.

On the day of the study at 8 a.m. a scalp vein needle was inserted into a forearm vein. The needle was filled with a saline-heparin solution after each blood sampling. Blood samples were obtained every hour from 8 a.m.11 p.m. and every 2 hours thereafter. During the 3 studies the patient was having exactly the same diet. The children went to sleep between 8 and 9 p.m. Blood samples were centrifuged immediately after collection and the plasma was kept frozen at $-20^{\circ} \mathrm{C}$ until determination.

HGH levels were determined by a double-antibody radioimmunoassay method based on that described for insulin by Morgan and Lazarow (1963) as modified by Jackson, Grant, and Clayton (1968). The standard and iodinated HGH $\left({ }^{125} \mathrm{I}\right)$ of the 'KIT' CEA-CEN- 
SORIN (Centro Richerche Nucleari di Sallugia, Italy) were used. The sensitivity was $0.5 \mathrm{ng} / \mathrm{ml}$.

All specimens of the 3 studies for each subject were analysed on the same day.

\section{Results}

The night and day growth hormone levels in the 5 children studied are shown in Fig. 1-5. Significant peaks of growth hormone were noted in all 5 children studied before treatment while an almost complete disappearance of these peaks was observed when the rhythm was repeated after therapy with corticosteroids and ACTH.

In Table I the recorded peaks (levels of growth hormone above $6 \mathrm{ng} / \mathrm{ml}$ ) are shown. In the pretreatment rhythm several high values were obtained while no peaks or very few were seen after administration of prednisone and ACTH. The only peak that was observed during ACTH administration (Case 4) could be attributed to stress.

\section{TABLE I}

Peaks of Plasma HGH During the 24 Hours $(H G H<6 n g / m l)$

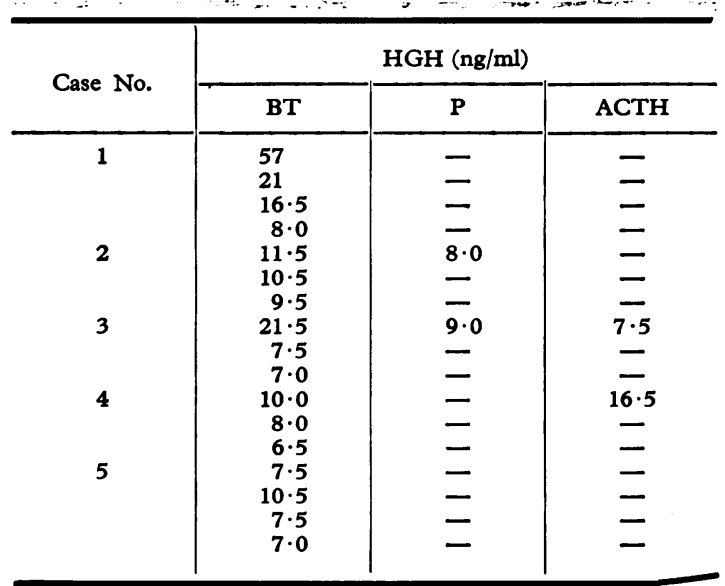

Note: $\mathrm{BT}=$ before treatment; $\mathrm{P}=$ prednisone.

Table II shows the results of planimetry of the three HGH curves for each patient. As can be seen the mean percentage surface occupied during prednisone and ACTH administration was half of that occupied during the pretreatment rhythm.

\section{Discussion}

Hunter and Rigal (1966), Honda et al. (1969), and Parker et al. (1969) have shown recently that HGH fluctuates during the 24 hours and according to Honda et al. (1969) and Parker et al. (1969), high
TABLE II

Plasma HGH Levels During the 24 Hours as Estimated by Planimetry

\begin{tabular}{c|c|c|c}
\hline \multirow{2}{*}{ Case No. } & \multicolumn{3}{|c}{ Surface Area (cm $\left.{ }^{2}\right)$} \\
\cline { 2 - 3 } & BT & P & ACTH \\
\hline 1 & 177 & 41 & 66 \\
2 & 90 & 40 & 11 \\
3 & 99 & 72 & 66 \\
4 & 62 & 19 & 44 \\
5 & 78 & 63 & 53 \\
\hline $\begin{array}{l}\text { Mean surface } \\
\text { area }\end{array}$ & 101 & 47 & 48 \\
\hline
\end{tabular}

Note: $\mathrm{BT}=$ before treatment; $\mathrm{P}=$ prednisone.

levels are a constant finding after the onset of sleep. Parker et al. (1969) suggested that the HGH regulatory effect on growth might be mediated through these peaks.

The present results show clearly that corticosteroid therapy has a pronounced effect on the spontaneous plasma levels of $\mathrm{HGH}$ in the sense that the normally observed peaks of $\mathrm{HGH}$ secretion are almost totally abolished (Fig. 1-5 and Table I) while measurable amounts of HGH less than 6 $\mathrm{ng} / \mathrm{ml}$ are still present (Fig. 1-5). The disappearance of these peaks has as a consequence a reduction of the total HGH as it is obvious from the results of the planimetry (Table II). The above findings could possibly suggest that growth retardation during corticosteroid treatment is mediated through these changes of $\mathrm{HGH}$ secretion.

The question as to whether growth retardation occurs during ACTH treatment has not yet been settled (Friedman and Strang, 1966; Norman and Sanders, 1969). The absence of any difference, however, in the HGH levels after prednisone and ACTH therapy suggests that any differences between corticosteroids and ACTH with respect to growth cannot be explained on the basis of differences of $\mathrm{HGH}$ during these treatments. Zahnd, Nadeau, and von Mühlendahl (1969) have reported that intravenous administration of large doses of synthetic ACTH acutely increases the plasma HGH level. The absence of any such change after ACTH treatment in the present study supports the previously expressed opinion by Ikkos et al. (1970) and Velentzas et al. (1971) that this increase is a pharmacological effect of ACTH.

The mechanism of the effect of corticosteroids and corticotrophin on the night and day rhythm of HGH that we have observed is not clear. Takahashi, Kipnis, and Daughaday (1968) have shown that peak HGH secretion is not correlated with 

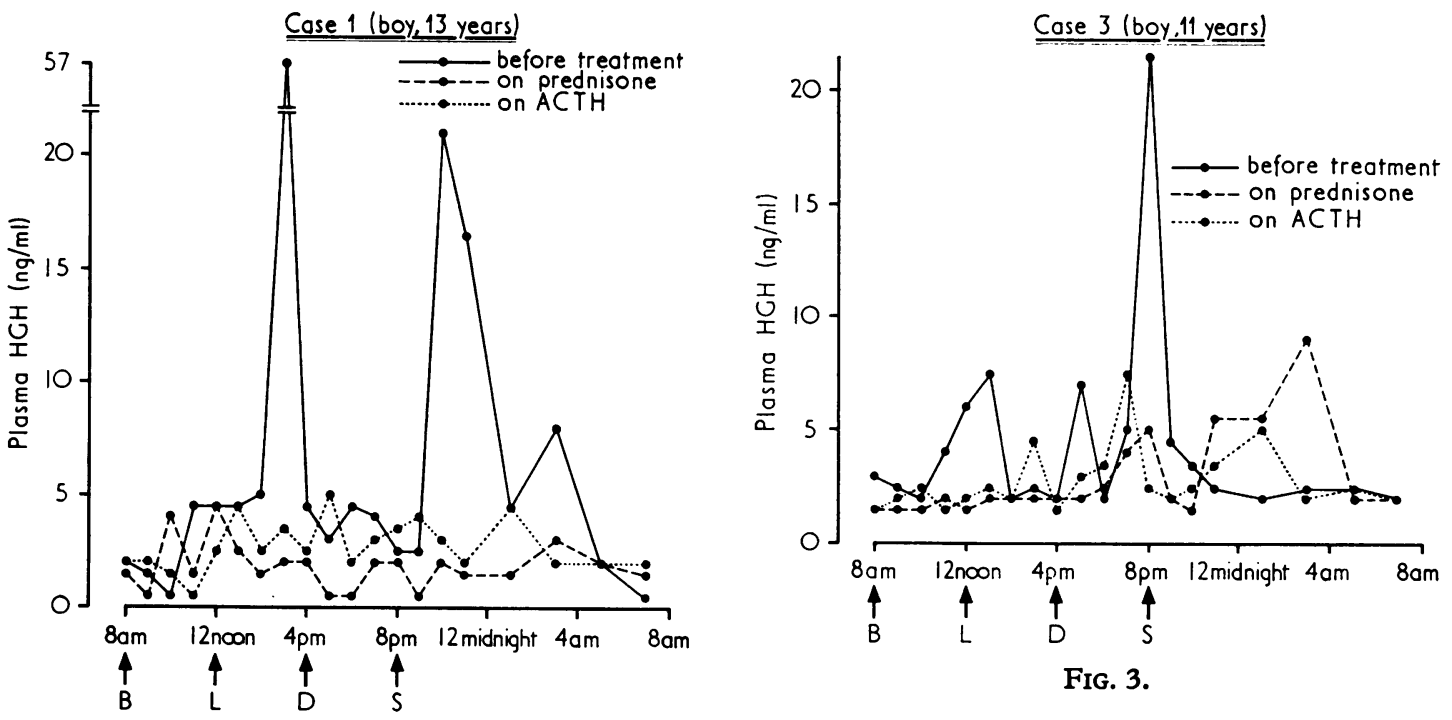

FIG. 1.

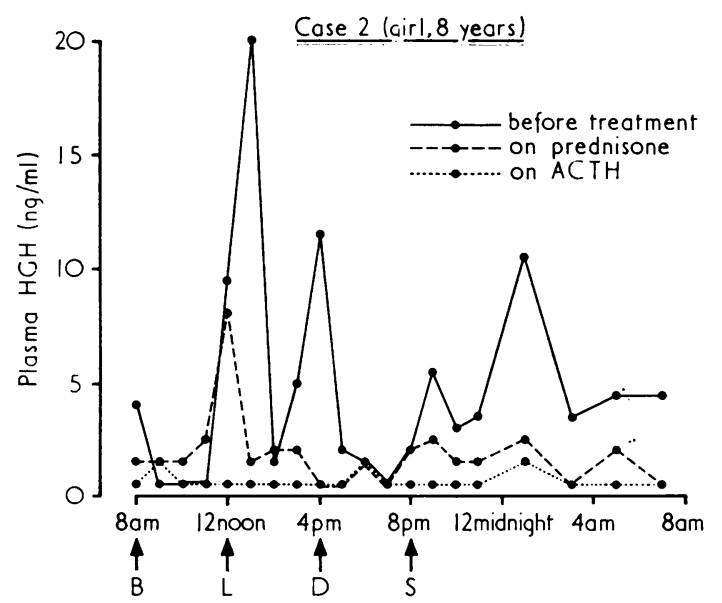

FIG. 2.

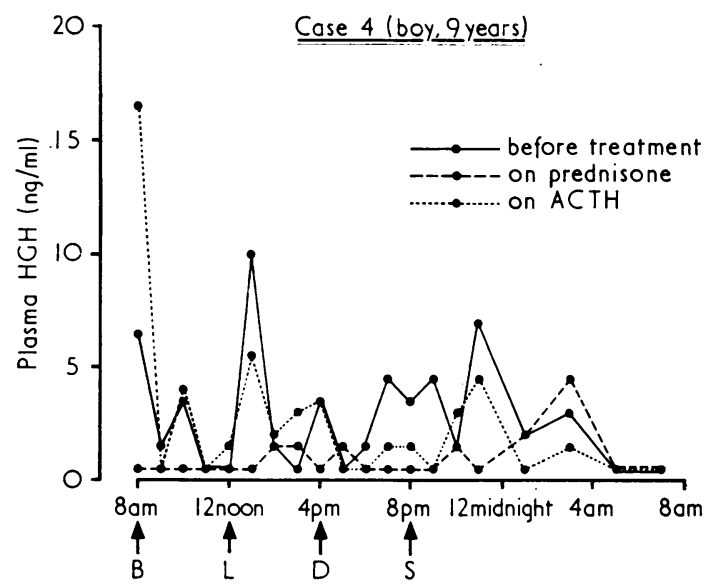

FIg. 4.

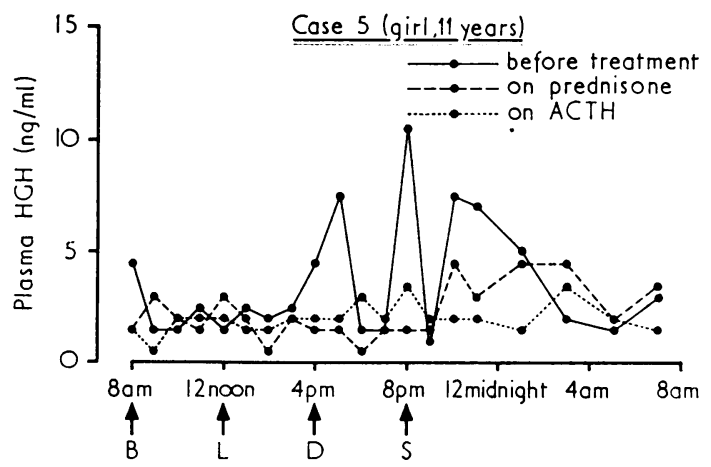

Fig. 5.

Fig. 1-5.-Night and day HGH levels before treatment and during prednisone and ACTH administration. The arrows indicate the time of breakfast $(B)$, lunch $(L)$, dinner $(D)$, and supper $(S)$. 
changes in plasma glucose, insulin, and cortisol. On the other hand, Pecile and Müller (1966) have shown that corticosteroids given to animals suppress the $\mathrm{HGH}$ release through an action involving the hypothalamic control of $\mathrm{HGH}$ secretion.

\section{REFERENCES}

Blodgett, F. M., Burgin, L., Iezzoni, D., Gribetz, D., and Talbot, N. B. (1956). Effects of prolonged cortisone treatment on the statural growth, skeletal maturation and metabolic status of children. New England fournal of Medicine, 254, 636.

Daly, J. R., and Glass, D. (1971). Corticosteroid and growthhormone response to hypoglycaemia in patients on long-term treatment with corticotrophin. Lancet, 1, 476.

Falliers, C. J., Tan, L. S., Szentivanyi, J., Jorgensen, J. R., and Bukantz, S. C. (1963). Childhood asthma and steroid therapy as influences on growth. American fournal of Diseases of Children, 105, 127.

Frantz, A. G., and Rabkin, M. T. (1964). Human growth hormone. New England fournal of Medicine, 271, 1375.

Friedman, M., and Stimmler, L. (1966). Effect of corticotrophin on growth-hormone secretion in response to insulin-induced hypoglycaemia in children. Lancet, $2,944$.

Friedman, M., and Strang, L. B. (1966). Effect of long-term corticosteroids and corticotrophin on the growth of children. Lancet, 2, 568.

Hartog, M., Gaafar, M. A., and Fraser, R. (1964). Effect of corticosteroids on serum growth hormone. Lancet, 2, 376.

Honda, Y., Takahashi, K., Takahashi, S., Azumi, K., Irie, M., Sakuma, M., Tsushima, T., and Shizume, K. (1969). Growth hormone secretion during nocturnal sleep in normal subjects. Fournal of Clinical Endocrinology and Metabolism, 29, 20.

Hunter, W. M., and Rigal, W. M. (1966). The diurnal pattern of plasma growth hormone concentration in children and adolescents. Fournal of Endocrinology, 34, 147.

Ikkos, D., Pantelakis, S., Katsichtis, P., and Velentzas, C. (1970). Effect of corticotrophin on plasma-growth-hormone. (Letter to the Editor.) Lancet, 1, 1401.
Jackson, D., Grant, D. B., and Clayton, B. E. (1968). A simple $\Omega$ oral test of growth-hormone secretion in children. Lancet, 2 , 373.

Morgan, C. R., and Lazarow, A. (1963). Immunoassay of insulin: two antibody system. Plasma insulin levels of normal, sub- $\overline{\bar{C}}$ diabetic and diabetic rats. Diabetes, 12, 115.

Morris, H. G., Jorgensen, J. R., and Jenkins, S. A. (1968). Plasma growth hormone concentrations in corticosteroid-treated $\bar{O}$

children. Fournal of Clinical Investigation, 47, 427.
Norman, A. P., and Sanders, S. (1969). Effect of corticotrophin $\frac{\overline{\overline{\mathcal{S}}}}{\supset}$ on skeletal maturation and linear growth in six patients with $\mathbb{D}$ severe asthma. Lancet, 1, 287.

Parker, D. C., Sassin, J. F., Mace, J. W., Gotlin, R. W., and Ross- () man, L. G. (1969). Human growth hormone release during sleep: electroencephalographic correlation. Fournal of Clinical $\vec{\circ}$ Endocrinology and Metabolism, 29, 871.

Pecile, A., and Müller, E. (1966). Suppressive action of corti- $\overrightarrow{\vec{\omega}}$ costeroids on the secretion of growth hormone. Fournal of $\vec{\omega}$ Endocrinology, 36, 401.

Root, A. W., Rosenfield, R. L., Bongiovanni, A. M., and Eberlein, ֶి W. R. (1967). The plasma growth hormone response to ? insulin-induced hypoglycemia in children with retardation of growth. Pediatrics, 39, 844.

Takahashi, Y., Kipnis, D. M., and Daughaday, W. H. (1968). N Growth hormone secretion during sleep. Fournal of Clinical $\triangle$ Investigation, 47, 2079.

Van Metre, T. E., Jr., and Pinkerton, H. L., Jr. (1959). Growth suppression in asthmatic children receiving prolonged therapy with prednisone and methylprednisolone. fournal of Allergy, 윽 30, 103.

Velentzas, C., Ikkos, D., Katsichtis, P., and Pantelakis, S. (1971). Stimulation of $\mathrm{HGH}$ secretion with $\beta^{1-24}$ synthetic corticotrophin in chronic adrenocortical insufficiency. (Greek) Iatriki Athinai, 19, 283.

Zahnd, G. R., Nadeau, A., and von Mühlendahl, K. E. (1969). Effect of corticotrophin on plasma levels of human growth $\vec{\theta}$ hormone. Lancet, 2, 1278.

Correspondence to Dr. C. A. Sinaniotis, Institute of Child Health, Goudi, Athens 608, Greece. 